\title{
The anorectic effect of oestradiol does not involve changes in plasma and cerebrospinal fluid leptin concentrations in the rat
}

\author{
M Rocha, E Grueso and M Puerta \\ Department of Animal Biology II (Physiology), Faculty of Biological Sciences, Complutense University, 28040 Madrid, Spain \\ (Requests for offprints should be addressed to M Puerta; Email: mpuerta@eucmax.sim.ucm.es)
}

\begin{abstract}
Oestradiol is a potent anorectic agent that reduces both food intake and body weight. Since leptin is known to reduce food intake, we first analysed if the anorectic effect of oestradiol is driven by an increased leptin concentration in either cerebrospinal fluid or plasma. Oestradiol also reduces body weight and fat mass. Accordingly, a decrease in plasma leptin concentration can also be expected after an oestradiol-driven reduction in fat mass. To test this hypothesis was the second aim of this study. Female Wistar rats received oestradiol chronically during 14 days. During the first week of treatment there was a reduction in
\end{abstract}

food intake, body weight and fat mass that returned to initial values during the second week, but no changes in ob mRNA levels were found in white adipose tissue depots. There was no effect of treatment or time on plasma and cerebrospinal fluid leptin concentrations. Therefore, the anorectic effect of oestradiol is not driven by an increase in leptin concentration either in plasma or in cerebrospinal fluid, and the reduction in fat mass that oestradiol produces is not followed by a reduction leptin concentration.

Journal of Endocrinology (2001) 171, 349-354

\section{Introduction}

It has been shown that white adipose tissue (WAT) produces the hormone leptin, the plasma concentration of which is directly related to the amount of body fat (Considine et al. 1996, Pratley et al. 1997, Greenberg \& Boozer 1999) and is therefore considered to be the messenger signalling the size of the fat store to the central nervous system (CNS), in agreement with the lipostatic theory (Kennedy 1953, Hausberger 1959). On a shortterm basis, plasma leptin concentrations also follow food intake patterns so that, despite an essentially unchanged amount of WAT during a $24 \mathrm{~h}$ cycle, nocturnal ingestive episodes in rats increase plasma leptin concentration, whereas no intake during the inactive phase of the cycle or fasting, decreases it (Ahima et al. 1996, Weigle et al. 1997, Pickavance et al. 1998). Therefore, leptin is considered both a lipostatic and a satiating signal.

The effects of oestradiol on energy balance have been known for a long time. Thus ovariectomized (ovx) rats receiving either daily injections or subcutaneous implants of oestradiol show both a reduced food intake and a reduced body weight (Wade 1975, Richard 1986) effects that are also evident in intact rats (Puerta et al. 1990). These effects are probably driven by actions of oestradiol at a central level, as its administration to the hypothalamic nuclei of rats reduces food intake (Butera et al. 1990, Dagnault \& Richard 1997, Lindblom et al.
2000). However, it can be argued that an enhancement of the leptin concentration either in plasma or in cerebrospinal fluid (CSF) could be involved. Certainly, oestradiol has been shown to increase $o b$ mRNA expression in WAT of ovx rats (Shimizu et al. 1997, Brann et al. 1999) and in adipocytes isolated from ovx rats (Machinal et al. 1999), this increase being followed by an enhanced concentration of leptin in the culture medium. A single dose of oestradiol in ovx rats also increased plasma leptin concentration (Brann et al. 1999). The first aim of this study was therefore to determine if the anorectic effect of oestradiol was mediated by an increase in leptin concentration. It can also be reasoned that, as soon as food intake decreases, a decrease in plasma leptin concentration could be expected - a decrease that would be even greater once the concomitant body weight loss (and hence fat mass) began. In this way, the decreased leptin concentrations would counterbalance the oestradiol-induced reduction in food intake. The second aim of the study was to investigate this hypothesis.

\section{Materials and Methods}

Female Wistar rats, 200-220 g body weight, were acclimated to $28{ }^{\circ} \mathrm{C}$ (thermoneutrality). On day 0 of the experiment ( $221 \pm 1 \mathrm{~g}$ body weight), $50 \%$ of the animals received one $17 \beta$-oestradiol-filled Silastic capsule (Dow 
Corning, MI, USA; $0.5 \mathrm{~cm}$ long; $3.2 \mathrm{~mm}$ o.d.; $1.5 \mathrm{~mm}$ i.d.). Control rats received empty implants. Capsules were inserted subcutaneously with the animal under ether anaesthesia. This method ensures a constant release of the hormone, increasing its plasma concentration for more than 1 month (Smith et al. 1977, Richard 1986, Nava et al. 1994). Rats were housed in individual cages with food and water available ad libitum and with a darkness:light cycle of $12 \mathrm{~h}: 12 \mathrm{~h}$, lights on at $0800 \mathrm{~h}$. The food provided was a commercial diet (Panlab, Barcelona, Spain) containing: $66 \cdot 7 \%$ carbohydrate, $19 \cdot 3 \%$ protein, $3 \cdot 4 \%$ fat, $4 \cdot 9 \%$ cellulose and $5 \cdot 7 \%$ mineral (w/w). Food intake and body weight were monitored daily. Food intake was measured by weighing what remained in the food cup. Animals were cared for and used in accordance with the principles of The Council of European Communities (86/609 EEC).

Both control and treated animals were killed (by decapitation) at different times (days 2, 8 and 14) during the experiment, between $1100 \mathrm{~h}$ and $1300 \mathrm{~h}$. Just before the animal was killed, and with the animal under ether anaesthesia, CSF was obtained by the insertion of a 23-gauge butterfly needle into the cisterna magna and the gentle withdrawal of 80-100 $\mu$ l CSF. Only samples without any blood contamination were processed. Vaginal smears were taken to corroborate the efficacy of treatment in oestradiol-treated rats. Blood was collected in a heparinized glass tube $(10 \mathrm{IU} / \mathrm{ml})$. Right-side WAT pads-inguinal, parametrial and retroperitoneal-were removed and immediately frozen in liquid $\mathrm{N}_{2}$ and stored at $-80{ }^{\circ} \mathrm{C}$ until required for analysis. Left-side pads inguinal, parametrial, retroperitoneal, perirenal and periovaric-were weighed. Total depot weight was calculated as twice the left-side pad weight. The abundance of WAT was estimated as an adiposity index modified for that described previously (Taylor \& Phillips 1996) and calculated as the sum of inguinal, parametrial, retroperitoneal, perirenal and periovaric depots divided by body weight and multiplied by 100 .

Total cellular RNA was extracted using Ultraspec RNA reagent (Biotecx Laboratories, TX, USA), a modified procedure of the single-step method reported for total RNA isolation (Chomczynski \& Sacchi 1987). RNA fractionation, blotting, hybridization and chemiluminescent detection were carried out according to previously published procedures (Trayhurn et al. 1994). In brief, RNAs were fractionated by agarose gel electrophoresis, transferred to a positively charged nylon membrane (Roche Molecular Biochemicals, Mannheim, Germany) by capillary blotting and crosslinked with UV light using a Foto/UV 21 (Fotodyne, WI, USA). The mRNA for $o b$ gene was detected using a 33-mer antisense oligonucleotide probe $5^{\prime}$-labelled with a single digoxigenin ligand (5'-GGT CTG AGG CAG GGA GCA GCT CTT GGA GAA GGC-3'). The membranes were incubated sequentially with the oligonucleotide and with an anti-digoxigenin serum alkaline phosphatase-conjugated antibody and processed essentially as in the procedures provided by Roche Molecular Biochemicals. CDP-star was used as the chemiluminescent substrate. Signals were visualized by exposing the membranes to a film (Hyperfilm ECL, Amersham Pharmacia Biotech, Amersham, Bucks, UK) and quantified by densitometry using NIH Image software. Membranes were stripped and reprobed for $18 \mathrm{~S}$ rRNA to check the loading and transfer of RNA during blotting. 18S rRNA was detected using a 31-mer antisense oligonucleotide probe (5'-CGC CTG CTG CCT TCC TTG GAT GTG GTA GCC G-3').

Blood was centrifuged at $2000 \mathrm{~g}$ for $15 \mathrm{~min}$ at $4{ }^{\circ} \mathrm{C}$. Plasma was withdrawn and stored at $-80{ }^{\circ} \mathrm{C}$ until required for analysis. Plasma leptin concentrations were determined with a commercially available rat leptin RIA kit (Linco Research, St Charles, MO, USA). The limit of sensitivity for assay was $0.5 \mathrm{ng} / \mathrm{ml}$ and the limit of linearity $50 \mathrm{ng} / \mathrm{ml}$. The intra- and interassay coefficients of variation were $4.6 \%$ and $5.7 \%$ respectively. CSF either from one rat or pooled from two rats was lyophilized and assayed by redissolution in a smaller volume than that indicated in the Linco kit for plasma samples. The other components of the kits were reduced accordingly. The standard curve obtained with reduced volumes was validated with the quality controls, as the values fitted their expected range. $\beta$-Hydroxybutyrate plasma concentration, measured as an index of starvation or severe fasting, was determined with a commercially available kit (Sigma Diagnostic, St Louis, MO, USA).

Two-way analysis of variance (ANOVA) was performed to compare WAT depot weight, plasma and CSF leptin concentrations, $\beta$-hydroxybutyrate plasma concentration and adiposity index, time and treatment being the variable factors. A Student-Newman-Keuls test was used for post hoc comparisons. Food intake, body weight and $o b$ mRNA levels were evaluated by an unpaired Student's $t$-test between corresponding control and treated animals (Mann-Whitney U-test was used when data did not show Gaussian distribution). $P<0 \cdot 05$ was considered as statistically significant.

\section{Results}

All rats receiving oestradiol had oestrus-like vaginal smears. Food intake was severely decreased on oestradiol administration, but this effect was transitory and disappeared after 7 days of treatment. The greatest decrease took place on day 3 of treatment, when food intake in treated rats was only $80 \%$ that of the control group $(P<0.05$; Fig. 1$)$. Body weight reflected the reduction in food intake so that, after only 3 days of treatment, treated animals showed a reduced body weight, which was $95 \%$ of that in controls $(P<0 \cdot 05)$. Again this effect was transient, differences disappearing after 8 days of treatment (Fig. 1). 

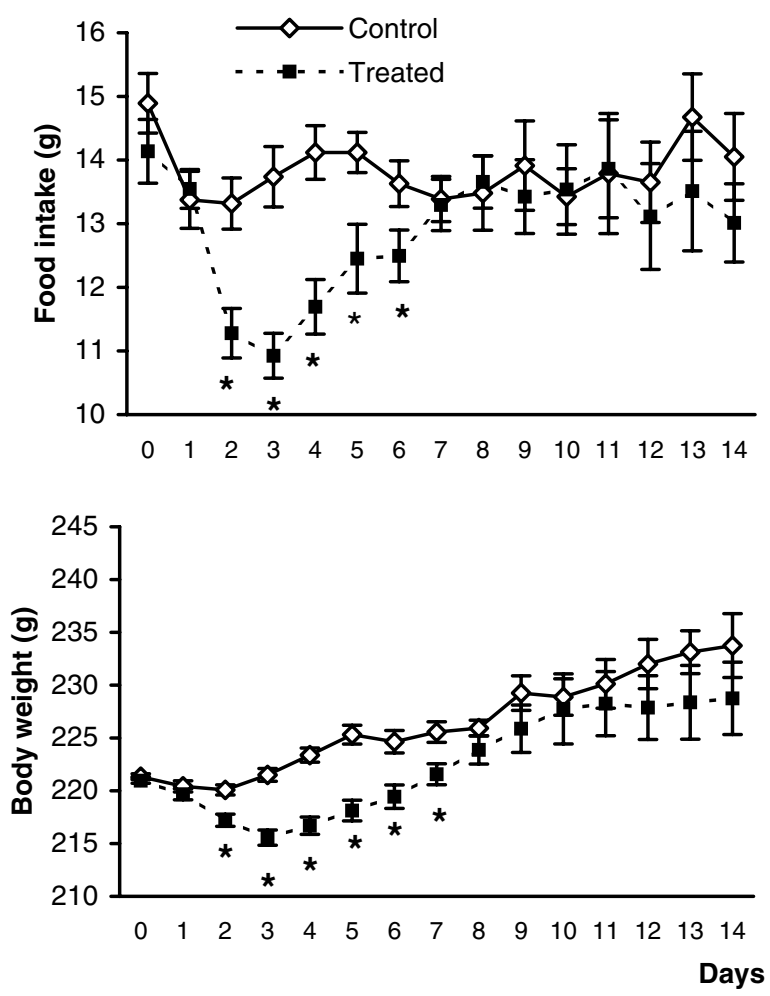

Figure 1 Daily food intake and body weight in rats receiving oestradiol chronically. Each point represents the mean \pm S.E.M. of results from 24 animals at days $0-2,16$ at days $3-8$ and eight at days 9-14. ${ }^{*} P<0.05$ compared with the respective control rats by Student's $t$-test (or a Mann-Whitney U-test on day 0 for food intake and on days 0 and 2 for body weight).

Figure 2 depicts the changes in individual WAT depots. Inguinal and parametrial depot weight were significantly lighter $(P<0.05)$ on day 2 of treatment (Fig. 2). The entire retroperitoneal, perirenal and periovaric mass was also reduced in treated animals on day 2 , but the difference did not reach statistical significance (Fig. 2). No differences were found in WAT depot weight of control and treated rats on day 8 of treatment (Fig. 2). On day 14 of treatment, WAT depots were heavier in treated rats than in controls, although only the parametrial depot weight difference reached statistical significance $(P<0 \cdot 05)$. The adiposity index changed in parallel with changes in individual depot weight, so that it decreased after 2 days of treatment $(P<0 \cdot 05)$, was similar to control on day 8 and was greater than in controls on day $14(P<0 \cdot 05$; Table 1$)$. Figure 3 depicts ob mRNA levels as arbitrary units in inguinal, parametrial and retroperitoneal WAT depots. Treatment with oestradiol did not change the $o b$ mRNA level in any of the three depots at any time of treatment (Fig. 3).

There was no effect of treatment or time on plasma leptin concentration (Fig. 4). CSF leptin concentration
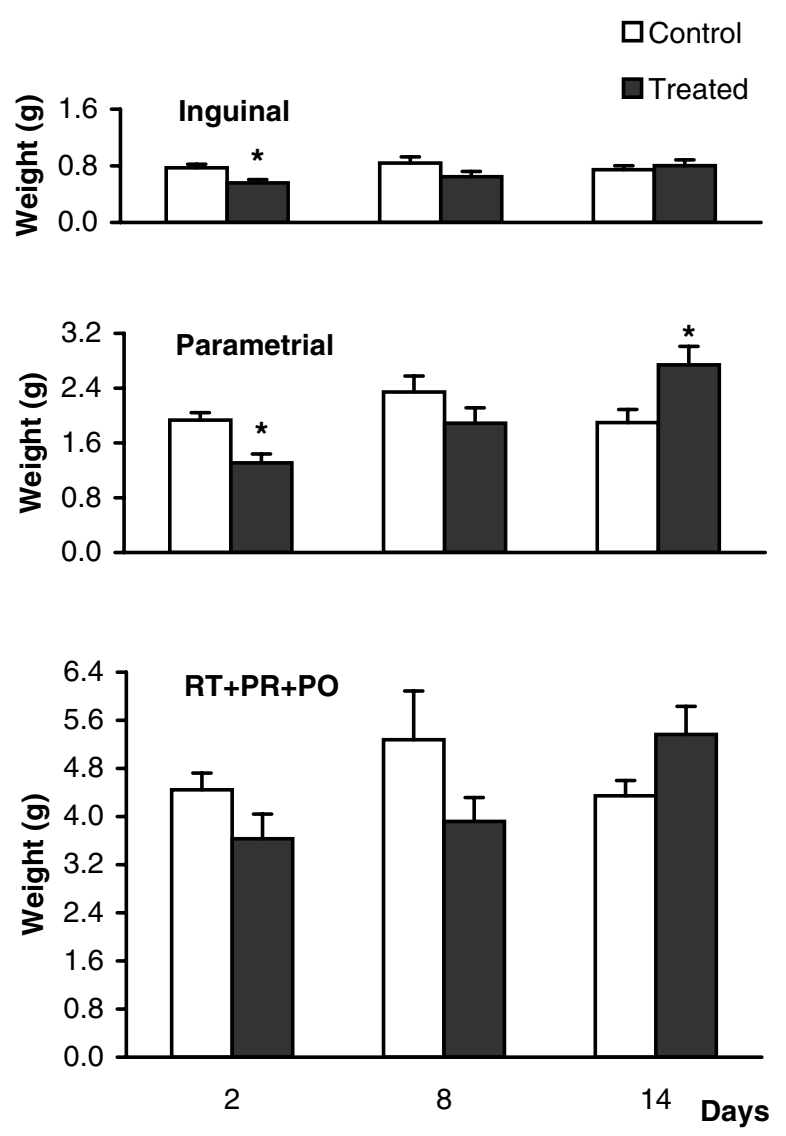

Figure 2 Weight of several WAT depots in rats receiving oestradiol chronically. Each bar represents the mean \pm S.E.M. of eight animals for inguinal and parametrial depots and four animals for the retroperitoneal (RT), perirenal (PR) and periovaric (PO) depots. ${ }^{*} P<0.05$ compared with respective controls.

was slightly decreased in treated animals on day 2 (Fig. 5) but the difference did not attain statistical significance. No differences in CSF leptin concentration were found on days 8 and 14 between treated and control rats (Fig. 5). There was no effect of treatment or time in plasma $\beta$-hydroxybutyrate concentration (Fig. 6).

Table 1 Adiposity index (sum of WAT depots $(\mathrm{g}) \times 100) /$ body weight $(\mathrm{g})$ in rats receiving oestradiol chronically. Values are means \pm S.E.M. $(n=4$ animals $)$

\begin{tabular}{|c|c|c|c|}
\hline & \multicolumn{3}{|c|}{ Adiposity index } \\
\hline & Day 2 & Day 8 & Day 14 \\
\hline Control & $3 \cdot 4 \pm 0 \cdot 2$ & $3 \cdot 8 \pm 0 \cdot 6$ & $3 \cdot 2 \pm 0 \cdot 2$ \\
\hline Treated & $2 \cdot 6 \pm 0 \cdot 2^{*}$ & $3 \cdot 0 \pm 0 \cdot 3$ & $4 \cdot 1 \pm 0 \cdot 3$ * \\
\hline
\end{tabular}

${ }^{*} P<0.05$ compared with respective control.

Journal of Endocrinology (2001) 171, 349-354 
A.
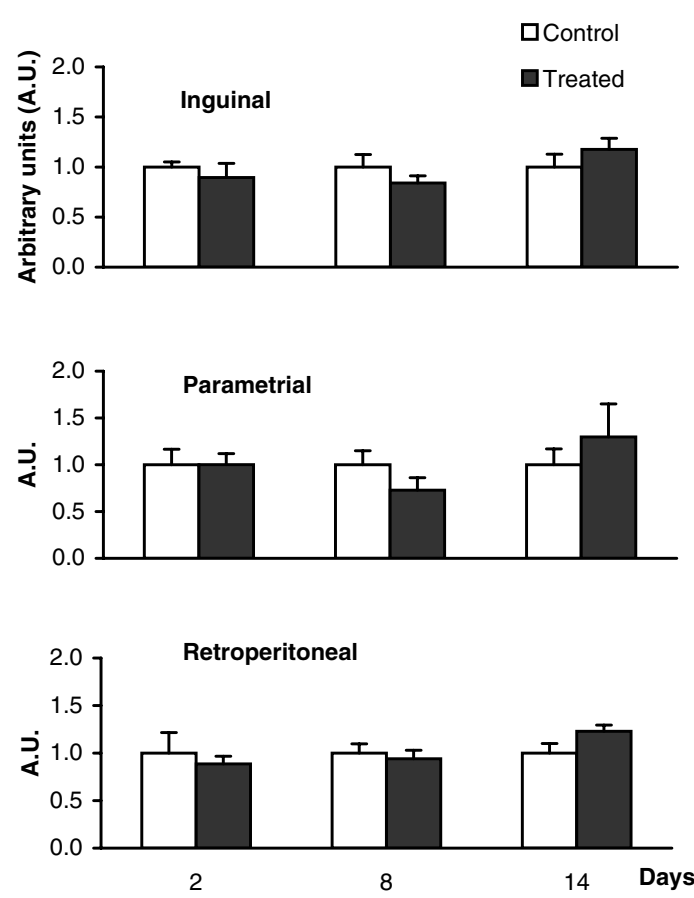

B.

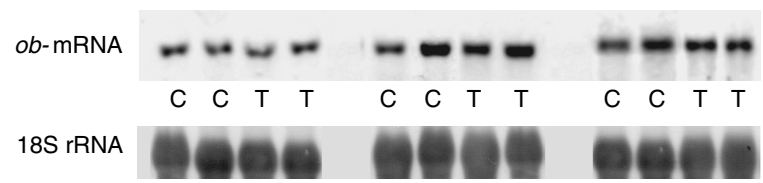

Figure 3 (A) ob mRNA levels in different WAT depots in rats receiving oestradiol chronically. Each bar represents the mean \pm S.E.M. of four to eight rats. (B) Northern blot of inguinal WAT at days 2, 8 and 14 of treatment. 18S rRNA was used to check loading and transfer.

\section{Discussion}

As expected, oestradiol treatment reduced food intake, in agreement with previous findings (Wade 1975, Richard 1986, Puerta et al. 1990). Thus, after 3 days receiving oestradiol, treated rats ate only $80 \%$ of the amount consumed by the controls. Nonetheless, no increase in plasma or CSF leptin concentration was found at that time, which excludes an increase in leptin signalling as the origin of the reduction in food intake. The oestradiol-driven reduction in food intake reduced the body weight of the treated animals to $95 \%$ the body weight of controls. A substantial part of this weight loss was due to fat loss, as judged by both the smaller weight of the WAT depots and the smaller adiposity index on day 2 . Both reduced food intake (Ahima et al. 1996, Weigle et al. 1997, Pickavance et al.

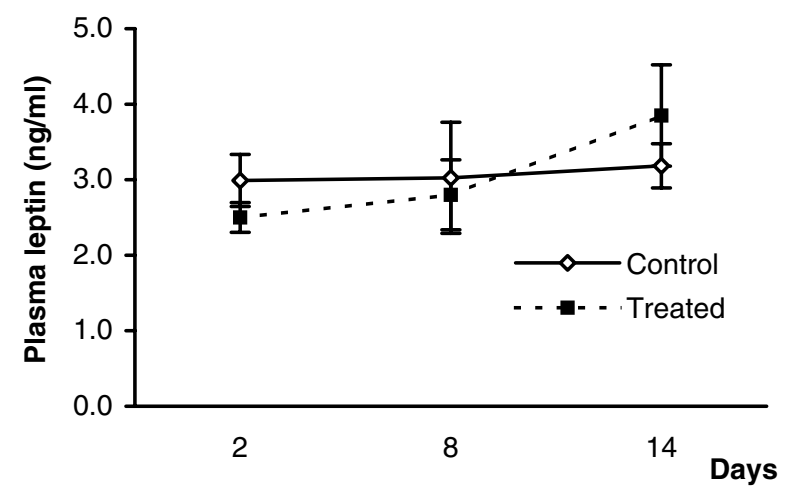

Figure 4 Plasma leptin concentration in rats receiving oestradiol chronically. Each point represents the mean \pm S.E.M. of four to six animals.

1998) and reduced fat mass (Greenberg \& Boozer 1999), are known to be followed by decreased plasma leptin concentration. However, despite the presence of both

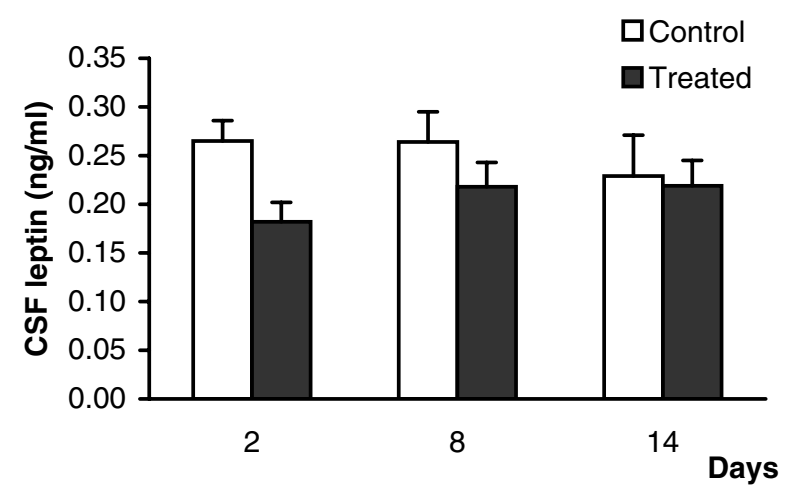

Figure 5 CSF leptin concentration in rats receiving oestradiol chronically. Each bar represents the mean \pm S.E.M. of four to six samples.

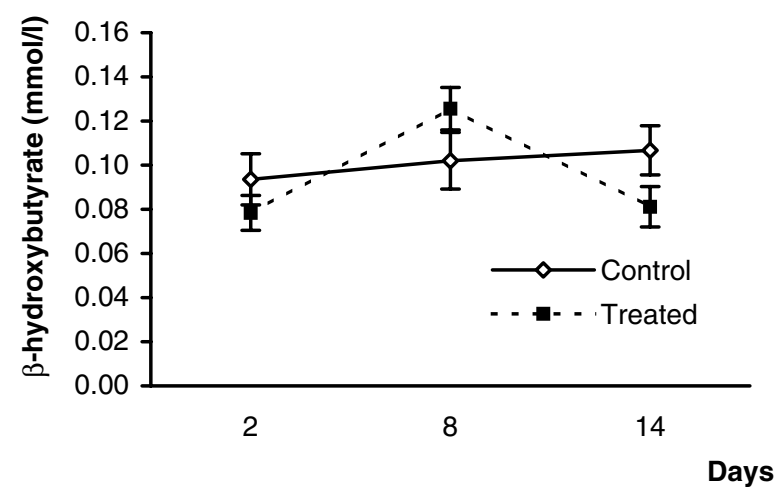

Figure $6 \beta$-Hydroxybutyrate plasma concentration in rats receiving oestradiol chronically. Each point represents the mean \pm S.E.M. of seven or eight animals. 
these negative influences - reduced food intake and fat loss - in our rats on day 2, no decrease in either ob mRNA levels in WAT or in plasma leptin concentration were found, which meant that the compensatory increase in food intake predicted by the adipostatic theory was not taking place. Therefore, it appears that, to allow the sustained reduction in food intake we have observed, other compensatory factors promoting leptin synthesis were also taking place. Indeed, oestradiol has been shown to increase $o b$ mRNA expression in WAT of ovx rats (Shimizu et al. 1997, Brann et al. 1999) and in adipocytes isolated from ovx rats (Machinal et al. 1999), this increase being followed by an enhanced leptin concentration in the culture medium. A single dose of oestradiol also increased plasma leptin concentration in ovx rats (Brann et al. 1999). This peripheral stimulatory action of oestradiol should be taken into consideration in our treated rats, in which it was most probably a contributory factor determining the actual plasma leptin concentration. Summing up, our results indicate that, when the plasma oestradiol concentration increases, a decrease in food intake supervenes, with a concomitant reduction in fat mass and body weight. However, in contrast to what might be expected from the adipostatic and satiating roles of leptin, neither an increase in plasma or CSF leptin concentrations as the origin of reduced food intake was found, nor did any reduction in plasma leptin or CSF concentrations take place after food intake and fat mass reduction. Indirectly, our results suggest that oestradiol brings about its effect on food intake by acting at a central level, probably acting upon nervous nuclei controlling food intake and satiation, as suggested by others (Butera et al. 1990, Dagnault \& Richard 1997, Lindblom et al. 2000). The similar leptin concentrations in both CSF and plasma of control and treated rats also suggest that oestradiol does not change leptin entrance into the CNS, although this was not demonstrated in.our study. Nonetheless, results presented in this paper do not exclude oestradiol modulating hypothalamic leptin sensitivity as another mechanism to reduce food intake. Leptin CSF values observed in our study are in agreement with those previously published for rats (Ishizuka et al. 1998, Grueso et al. 2001).

Seven days after the implantation of the Silastic capsules, food intake had returned to that of untreated controls. After 14 days of treatment, body weight of treated rats was almost similar to that of controls. However, the plasma oestradiol concentration was still increased at that time (Nava et al. 1994). In other words, the effects of oestradiol were not permanent, which is in agreement with previous findings (Wade 1975). Certainly, if present for a long period of time, the potent negative effect of oestradiol on energy balance could lead to potentially fatal body weight losses. Therefore, the existence of a control mechanism is not surprising. Our results showed that, in intact rats, the anorectic effects of oestradiol were evident for 3 days, but from this time onwards they become less potent until they disappeared, which suggest a desensitization process. The 3-day period of time before the initiation of the suggested desensitization would allow oestradiol to exert its anorectic effect to the full during the physiological increases in the hormone - that is, during the $10-12 \mathrm{~h}$ of pro-oestrus in every oestrus cycle (Ter Haar 1972, Butcher et al. 1974, Wade 1976) and during the last day of pregnancy (Lu et al. 1998). It seems reasonable to argue that those anorectic episodes could be beneficial either for mating or for labour respectively, as they release the female from the constrains of searching for food during those periods of time.

\section{Acknowledgements}

This work was supported by grants 08·6/0007/1998 from CAM and PM98-0090 from D.G.E.S.I.C. to M Puerta. M Rocha was the recipient of a predoctoral scholarship from U.C.M.

\section{References}

Ahima RS, Prabakaran D, Mantzoros C, Qu D, Lowell B, MaratosFlier E \& Flier JS 1996 Role of leptin in the neuroendocrine response to fasting. Nature 382 250-252.

Brann DW, De Sevilla L, Zamorano PL \& Mahesh VB 1999 Regulation of leptin gene expression and secretion by steroid hormones. Steroids 64 659-663.

Butcher RL, Collins WE \& Fugo NW 1974 Plasma concentration of LH, FSH, prolactin, progesterone and estradiol-17 $\beta$ throughout the 4-day estrous cycle of the rat. Endocrinology 94 1704-1708.

Butera PC, Beikirch RJ \& Willard DM 1990 Changes in ingestive behaviors and body weight following intracranial application of 17 alpha-estradiol. Physiology and Behavior 47 1291-1293.

Chomczynski P \& Sacchi N 1987 Single-step method of RNA isolation by acid guanidinium thiocyanate-phenol-chloroform extraction. Analytical Biochemistry 162 156-159.

Considine RV, Sinha MK, Heiman ML, Kriauciunas A, Stephens TW, Nyce MR, Ohannesian JP, Marco CC, McKee LJ, Bauer TL \& Caro JF 1996 Serum immunoreactive-leptin concentrations in normal-weight and obese humans. New England Journal of Medicine 334 292-295.

Dagnault A \& Richard D 1997 Involvement of the medial preoptic area in the anorectic action of estrogens. American Journal of Physiology 272 R311-R317.

Greenberg JA \& Boozer CN 1999 The leptin-fat ratio is constant, and leptin may be part of two feedback mechanisms for maintaining the body fat set point in non-obese male Fischer 344 rats. Hormone and Metabolic Research 31 525-532.

Grueso E, Rocha M \& Puerta M 2001 Plasma and cerebrospinal fluid leptin levels are maintained despite enhanced food intake in progesterone-treated rats. European Journal of Endocrinology 144 659-665.

Hausberger FX 1959 Parabiosis and transplantation experiments in hereditarily obese mice. Anatomical Record 130313.

Ishizuka T, Ernsberger P, Liu S, Bedol D, Lehman TM, Koletsky RJ \& Friedman JE 1998 Phenotypic consequences of a nonsense mutation in the leptin receptor gene $\left(\mathrm{fa}^{\mathrm{k}}\right)$ in obese spontaneously hypertensive Koletsky rats (SHROB). Journal of Nutrition 128 2299-2306. 
Kennedy GC 1953 The role of depot fat in the hypotalamic control of food intake in the rat. Proceedings of the Royal Society of London B 140 578-592.

Lindblom J, Schioth HB, Watanobe H, Suda T, Wikberg JES \& Bergstrom L 2000 Downregulation of melanocortin receptors in brain areas involved in food intake and reward mechanisms in obese (OLETF) rats. Brain Research 852 180-185.

Lu CC, Tsai SC, Wang SW, Tsai CL, Lau CP, Shih HC, Chen YH, Chiao YC, Liaw C \& Wang PS 1998 Effects of ovarian steroid hormones and thyroxine on calcitonin secretion in pregnant rats. American Journal of Physiology 274 E246-E252.

Machinal F, Dieudonne MN, Leneveu MC, Pecquery R \& Giudicelli $\mathrm{Y} 1999$ In vivo and in vitro ob gene expression and leptin secretion in rat adipocytes: evidence for a regional specific regulation by sex steroid hormones. Endocrinology 140 1567-1574.

Nava MP, Fernández A, Abelenda M \& Puerta M 1994 Dissociation between brown adipose tissue thermogenesis and sympathetic activity in rats with high plasma levels of oestradiol. Pflügers Archiv European Journal of Physiology 426 40-43.

Pickavance L, Tadayyon M, Williams G \& Vernon RG 1998 Lactation suppresses diurnal rhythm of serum leptin. Biochemical and Biophysical Research Communications 248 196-199.

Pratley RE, Nicolson M, Bogardus C \& Ravussin E 1997 Plasma leptin responses to fasting in Pima Indians. American Journal of Physiology 273 E644-E649.

Puerta M, Nava MP, Abelenda M \& Fernández A 1990 Inactivation of brown adipose tissue thermogenesis by oestradiol treatment in cold-acclimated rats. Pflügers Archiv European Journal of Physiology 416 659-662.

Richard D 1986 Effects of ovarian hormones on energy balance and brown adipose tissue thermogenesis. American Journal of Physiology 250 R245-R249.
Shimizu H, Shimomura Y, Nakanishi Y, Futawatari T, Ohtani K, Sato N \& Mori M 1997 Estrogen increases in vivo leptin production in rats and human subjects. Journal of Endocrinology 154 285-292.

Smith ER, Damassa DA \& Davidson JM 1977 Hormone administration: peripheral and intracraneal implants. In Methods in Psychobiology, pp 259-279. Ed. RD Myers. New York: Academic Press.

Taylor BA \& Phillips SJ 1996 Detection of obesity QTLs on mouse chromosomes 1 and 7 by selective DNA pooling. Genomics 34 389-398.

Ter Haar MB 1972 Circadian and estrual rhythms in food intake in the rat. Hormones and Behavior 3 213-219.

Trayhurn P, Duncan JS, Nestor A, Thomas MEA \& Rayner DV 1994 Chemiluminescent detection of mRNAs on northern blots with digoxigenin end-labelled oligonucleotides. Analytical Biochemistry 222 224-230.

Wade GN 1975 Some effects of ovarian hormones on food intake and body weight in female rats. Journal of Comparative and Physiological Psychology 88 183-193.

Wade GN 1976 Sex hormones, regulatory behaviors, and body weight. In Advances in the Study of Behavior, pp 201-279. Eds JS Rosenblatt RA Hinde, E Show \& CG Beer. New York: Academic Press.

Weigle DS, Duell PB, Connor WE, Steiner RA, Soules MR \& Kuijper JL 1997 Effect of fasting, refeeding, and dietary fat restriction on plasma leptin levels. Journal of Clinical Endocrinology and Metabolism 82 561-565.

Received 26 June 2001

Accepted 9 July 2001 